\title{
CRIAÇÃO DE UM MAPA TÁTIL ATRAVÉS DA TECNOLOGIA ASSISTIVA: MAIS ACESSIBILIDADE AOS DEFICIENTES VISUAIS COM A UTILIZAÇÃO DA IMPRESSÃO 3D
}

\author{
Glaucia Soldati Dias \\ Universidade Federal de Juiz de Fora \\ glaucia-sd@hotmail.com \\ Ivan Mota Santos \\ Universidade Federal de Juiz de Fora \\ santos.ivan@gmail.com
}

Resumo: A vida dos deficientes, em geral, é provida de limitações e dificuldades, independentemente do tipo de deficiência, fato este agravado por alguns locais que não se adequam às suas restrições individuais. Como ocorre com os deficientes visuais, que possuem uma grande dificuldade de se locomoverem ao adentrar em um ambiente fechado e desconhecido. Diante disto, esta pesquisa tem o objetivo de identificar suas principais limitações, entender seu processo de montagem da imagem mental do ambiente e como conseguem acessar os locais de forma independente. Nota-se uma despreocupação dos órgãos públicos e privados com a locomoção dos deficientes visuais em suas edificações pouquíssimos prédios possuem sinalização tátil no piso ou qualquer outra forma de orientação espacial. Desta forma, elaborou-se um mapa tátil acessível para deficientes visuais, de maneira que seja de fácil replicação em diversos locais e com baixo custo. Utilizando a prototipagem rápida como mecanismo de produção, esta técnica permite a personalização e agilidade na fabricação do mesmo. Como exemplo para a confeç̧ão do mapa, foi utilizado o prédio do Instituto de Artes e Design (IAD) da Universidade Federal de Juiz de Fora.

Palavras-chave: Design de Produto. Mapa tátil. Deficiência Visual. Prototipagem Rápida. Impressão 3D

\begin{abstract}
In general, the life of disabled persons, independent of the type of disability, is full of limitations and obstacles, which is made worse by some locations that are not prepared for the individual necessities of each person. As an example, the visually impaired individuals have great problems walking in indoor and unfamiliar places, hence, the aim of this research is identify the main limitations, understand the process of memorization of the ambient, and how they are able to access the locations by theirself. It is easy to notice that public and private organizations do not give attention to the how the visually impaired individuals access their buildings - only a few constructions have tactile floor signals or other
\end{abstract}


devices that help with the spatial orientation. Thus, it was formulated a tactile map accessible to blind, which is easier to replicate in different places and to a lower cost. The fast prototyping was used as the mechanism of production, once this technic allows agility and customization to the production of the map. The Institute of Arts and Design (Instituto de Artes e Design - IAD) of the Federal University of Juiz de Fora (Universidade Federal de Juiz de Fora - UFJF) was used as a model to confection of the map.

Key-words: Product Design. Tactile Map. Visually Impaired. Rapid Prototyping. 3D Impression

\section{INTRODUÇÃO}

Um relato, apresentado pelo website da ONU, feito pela Organização Mundial da Saúde (OMS) em 2013, alega que existem 39 milhões de cegos no mundo, além de 246 milhões sofrerem de baixa visão, que seria a perda parcial da visão, e os países em desenvolvimento abrigam $90 \%$ desta população.

De acordo com o censo do Instituto Brasileiro de Geografia e Estatística (IBGE) de 2010, a deficiência visual foi a mais relatada entre os entrevistados, incluindo cegueira e baixa visão (dificuldade em enxergar), chegando a 35,7 milhões de pessoas em todo o país. Sendo, $18,8 \%$ dos entrevistados alegaram dificuldades para enxergar, ainda que utilizem lentes de correção. 506 mil pessoas informaram serem cegas. No município de Juiz de Fora, de acordo com o mesmo censo, existem 516.247 habitantes, destes 1.242 declararam-se cegos $(0,24 \%)$ e os que possuem uma grande dificuldade de enxergar são 13.689 (2,65\%).

Diante de tamanha expressividade pelos números apresentados, conclui-se que há uma necessidade pontual em atender estas pessoas. As limitações enfrentadas por estes em seu dia-a-dia poderiam ser facilmente evitadas, ou abrandadas, se no momento da elaboração de algum projeto, independente do segmento, fosse direcionado a eles, estendendo-se a outros tipos de deficiência, ou seja, gerando acessibilidade.

Uma das tecnologias que mais vem se tornando popular e acessível é a prototipagem rápida. Através da impressão 3D, por exemplo, se cria um enorme campo de possibilidades para integração dos deficientes visuais à sociedade. O objetivo deste trabalho refere-se à fabricação de um mapa tátil, elaborado para deficientes visuais, que auxilie na locomoção nas dependências do Instituto de Artes e Design da Universidade Federal de Juiz de Fora.

\section{DESENVOLVIMENTO}

\subsection{Pesquisa}

\subsubsection{Usuários}

Ser portador de deficiência visual traz uma limitação inestimável sobre sua independência de locomoção. Não encontramos, com a frequência necessária, ruas adaptadas ou ambientes com sinalizações suficientes. 
De acordo com Ferreira (2008) a chamada Cartografia Tátil é a responsável por ensinar importantes conceitos de orientação e mobilidade aos cidadãos cegos ou de baixa visão. A formação de uma imagem mental é de extrema importância para a percepção do ambiente e espaço, o que auxilia os deficientes visuais em sua locomoção diária de forma mais independente.

Um relevante elemento utilizado na cartografia é o mapa tátil, que contribui para que o deficiente visual compreenda o espaço ambiental e se planeje pelos melhores caminhos a percorrer. Diferentemente das maquetes táteis, as quais possuem delimitações de espaço e preocupa-se com a representação de detalhes arquitetônicos e do entorno (VERTORINI, 2007). Ressalta-se que estes tipos de recursos de referência tátil não substituem as sensações da experiência direta, mas são muito eficientes na transmissão de informações.

Existe um conjunto de Normas que auxiliam no deslocamento dos deficientes visuais, que devem ser aplicadas tantos em ambientes externos quanto internos. A ABNT NBR 9050 é a norma brasileira sobre acessibilidade a edificações, mobiliário, espaços e equipamentos urbanos.

De acordo com Milan (2008), o nível da deficiência é o fator que mais causa variações nos resultados das pesquisas, uma vez que existem os cegos e portadores de baixa visão. Os que possuem cegueira adquirida, por exemplo, podem apresentar diferença para aqueles que nasceram com a anomalia, e os de baixa visão ainda conseguem alguma vantagem, mesmo que com dificuldade.

\subsubsection{Cenário Sociocultural}

$\mathrm{Na}$ cidade de Juiz de Fora, muitos eventos que integram os deficientes visuais são promovidos pela Associação dos Cegos, juntamente com parceiros e apoiadores. A entidade abriga 32 pessoas com deficiência visual e estas pessoas recebem todo tipo de apoio, médico, sanitário, alimentício, lazer, social etc.

Dentro da instituição há diversas formas de integração para estas pessoas, lhes são oferecidos cursos de Braille, orientação e mobilidade, artesanato, informática, possuem biblioteca e alguns projetos pontuais.

Existem outras formas de atividades direcionada aos deficientes visuais, não se encontra registros em Juiz de Fora, mas em grandes centros ocorrem com mais frequência. Os museus vêm apresentando bastante interesse neste tipo de público. Já se encontram diversas exposições com obras táteis. Como em cinemas em que algumas redes fornecem a opção de audiodescrição. Além de uma infinidade de projetos de aplicativos de celular que buscam, à sua maneira, facilitar a vida dos usuários.

\subsubsection{Processos de fabricação e Materiais}

O processo utilizado no projeto é a impressão 3D, pois, além de ser acessível é uma tecnologia que está cada vez mais desenvolvida, com aprimoramentos significativos e resultados consideráveis.

Entretanto, mesmo com toda praticidade e benefícios do método, como todo processo de fabricação, existem os pontos negativos. Na maioria das vezes, este processo deixa a desejar nas propriedades mecânicas em relação aos metais e plásticos utilizados no produto final. "[...] devido ao fato de a fabricação ser por adição de camadas, o material possui certa anisotropia. Este fato implica em limitações na 
aplicação das peças produzidas por estes processos." (VOLPATO et al, 2007). O acabamento também não é o mesmo que aos produzidos por usinagem. A adição de camadas deixa a superfície com aspectos serrilhados e as partes inclinadas e curvas com um efeito de escada.

A impressora disposta no Instituto é de um modelo mais antigo e não há muitas possibilidades em relação ao material a ser utilizado. Dentre os disponíveis, o mais viável foi o PLA, também conhecido como ácido poliático, é um material biodegradável produzido a partir de ácido láctico natural do trigo, milho ou leite. Os objetos feitos com ele tendem a ter uma menor deformidade, acarretando mais eficiência em determinados tipos de moldagem. Para Ashby; Johnson (2011), o PLA é um material rígido, porém frágil, podendo ser composto para ampliar suas propriedades mecânicas. Além de permitirem maior durabilidade dos aparelhos, pois exige menos força das máquinas por ser menos viscoso em seu estado líquido.

Saindo um pouco do contexto de impressão 3D, a questão dos materiais é um elemento fundamental na construção de maquetes táteis convencionais. $O$ tato é um dos sentidos mais importantes para os cegos, até mesmo para quem possui visão, alguns elementos só são identificáveis pelo toque.

\footnotetext{
O emprego dos materiais adequados é de suma importância para a reprodução realista do espaço. Os materiais, por si só, apresentam informações perceptíveis através do tato que podem auxiliar o usuário na compreensão do ambiente. [...]

Quando a seleção desses materiais é feita da maneira correta, a imagem construída através da percepção tátil se aproxima da realidade, de forma a superar a barreira da comunicação entre a maquete e seus usuários.

(DIAS; ESTANISLAU; BAHIA, 2014).
}

\subsubsection{Benchmarking}

Encontram-se muitas pesquisas neste ramo voltadas para museus e bibliotecas. Justamente por ser uma categoria que não se apresenta muito interesse comercial, as pesquisas encontradas são elaboradas por universidades de ensino, em grande maioria. Tanto maquetes como mapas táteis são encontrados, cada um com sua particularidade. $O$ processo de prototipagem rápida é encontrado em alguns estudos, e também outros processos de formas distintas e convencionais.

Um projeto que utilizou a prototipagem rápida, foi a maquete tátil do Congresso Nacional (MOTTIN et al, 2008), desenvolvida pela UEMG de Belo Horizonte, a maquete foi produzida para um projeto do Congresso que busca a integração dos deficientes visuais nas dependências da unidade. Foi feita totalmente em impressão 3D e tem a principal finalidade de entendimento espacial da edificação. "O foco trabalhado para as necessidades da maquete foi a qualidade de materiais e acabamentos tanto para os deficientes quanto para os transeuntes não deficientes que teriam contato com ela" (MOTTIN et al, 2008). Obtiveram grande êxito na representação, conseguindo transmitir as sensações ideais de acordo com os materiais e texturas escolhidos. 

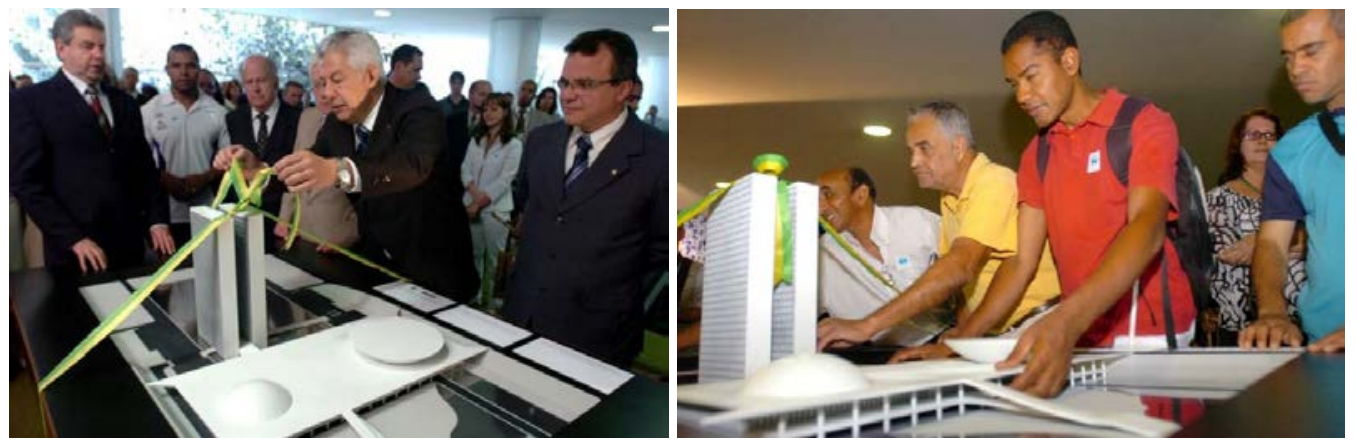

Figura 1 - Maquete tátil do Congresso Nacional no dia de sua inauguração. (MOTTIN et al, 2008).

Em alguns casos, como no projeto desenvolvido para a Biblioteca Central Cesar Lattes da Unicamp (D'ABREU, et al, 2007), utilizam mecanismos auditivos como complemento do manuseio, os sensores ao serem pressionados informam o local ao qual correspondem. Esta está mais próxima ao modelo de mapa tátil, onde seu foco principal é o tracejo de rotas no local, utilizada exclusivamente por deficientes visuais, não houve uma maior preocupação com sua parte estética.
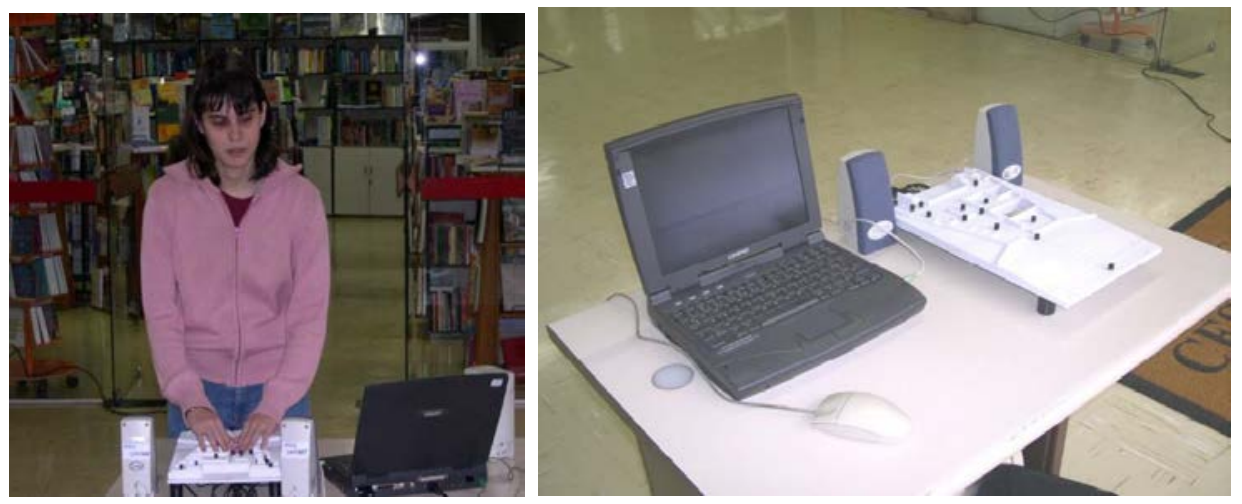

Figura 2 - Maquete tátil da Biblioteca Central Cesar Lattes da Unicamp. (D'Abreu et al, 2007).

Existem alguns mapas que são representados de forma mais simplória e possuem acesso ao público em geral, são os mapas disponíveis no Banco do Brasil e Caixa Econômica Federal, por exemplo, onde representam somente o trajeto oferecido pelo piso tátil, mantendo um padrão em todas as unidades e com alto contraste para facilitar aos portadores de baixa visão. 


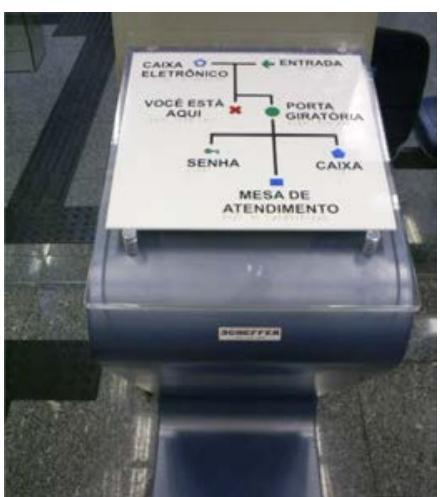

(a)

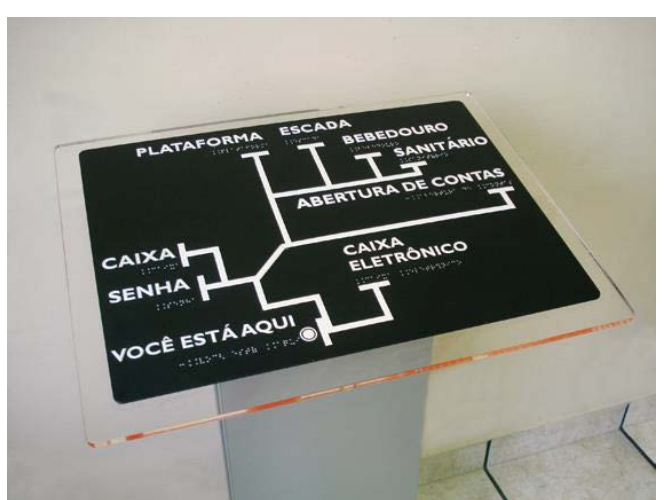

(b)

Figura 3 - Mapas táteis disponíveis no Banco do Brasil e Caixa Econômica Federal.

Em (a) apresenta o estilo de mapa encontrado nas agências do Banco do Brasil. As linhas representam o caminho fornecido pelo piso tátil e cada departamento possui um símbolo diferente, facilitando o entendimento. Fonte: Site da Internet1

Em (b) está representado o mapa tátil encontrado nas agências da Caixa Econômica Federal. O trajeto é mesmo apresentado pelo piso tátil. Fonte: Site da Internet2

Um fator relevante e encontrado em muitos casos foi a falta de cores nos elementos, geralmente monocromático (branco) por serem direcionados aos deficientes visuais. Não consideram que pessoas que enxergam também frequentam o mesmo ambiente, além de facilitar aos portadores de baixa visão, e uma valorização do design do modelo é fundamental para a valorização do projeto.

\subsection{Metodologia}

A metodologia empregada no projeto, baseia-se na bibliografia de Dijon de Moraes, o Metaprojeto. O método descrito em sua obra, relata a complexidade de se projetar atualmente. Pesquisas de marketing nem sempre são certeiras, além de dados estatísticos, deve-se compreender e interpretar as opiniões dos usuários. Em um cenário cada vez mais complexo, fluido e dinâmico, é preciso conhece-los bem antes de iniciar qualquer projeto.

É objetivo do metaprojeto propiciar um cenário existente ou futuro a partir de uma plataforma de conhecimentos, em que é demonstrada a prévia avaliação sobre os pontos positivos e negativos relacionados ao desenvolvimento dos produtos industriais [...]. (MORAES, 2010)

Os principais enfoques na metodologia são as pesquisas relacionadas ao ciclo de vida, processos de fabricação, materiais, fatores sociais e mercadológicos, coerência estético-formal e formas de uso.

O método aplicado pelo metaprojeto é mais dinâmico, diferentemente do método tradicional em que percorre as fases do projeto uma única vez, são feitas várias verificações em todas as etapas, incluindo feedbacks até mesmo nas fases já finalizadas.

\footnotetext{
${ }^{1}$ Disponível em: <https://thaisfrota.wordpress.com/2009/05/19/mapa-tatil/>. Acesso em: 27 de jan. 2016.

${ }^{2}$ Disponível em: <http://www.arcomodular.com.br/portugues/cases/bancos/caixa>. Acesso em: 27 de jan. 2016.
} 


\subsection{Conceito}

Na maioria dos casos, a produção de um mapa tátil provém de um processo trabalhoso, com maior interesse por acadêmicos universitários, as pesquisas ficam muito restritas às universidades de ensino e cada um no seu modo de fabricação, ou seja, falta uma linguagem mais padronizada. Além de tudo, os custos são altos e elaborar tais projetos demanda muito tempo e investimento, pois necessitam de um material apropriado e resistente.

Os resultados de pesquisas precisam atingir a população interessada, eles necessitam testar e aprimorar, cada vez mais, os resultados obtidos. Para que isto ocorra de forma mais proveitosa, o custo precisa ser baixo, precisa atrair os olhares de investidores e órgãos políticos responsáveis. Para que isto seja atribuído, o projeto precisa ter uma factibilidade de produção e criar uma padronização dos elementos. Seguir as normas estabelecidas não são suficientes, a linguagem como todo precisa ser unificada.

Destacando estas premissas, o conceito se trata de um objeto que seja mais acessível e seja espalhado em diversos locais pelo ambiente, facilitando nas consultas e evitando que o usuário se perca ou necessite decorar um ambiente muito grande em pouco tempo. As opções como "Você está aqui" são de extrema importância para que o deficiente se situe geograficamente.

\subsection{Opinião do usuário}

Durante a pesquisa deste projeto, a pesquisadora teve contato com diversas pessoas que possuem algum tipo de proximidade com deficientes visuais. A opinião de quem convive e ensina é de extrema importância para o desenvolvimento do projeto, mas não mais importante que a própria opinião do cego para relatar, realmente, quais suas principais necessidades e queixas.

O principal entrevistado foi o senhor José do Carmo Reis, residente de Juiz de Fora e portador de baixa visão, originada por glaucoma, e sua esposa Terezinha Martins de Araujo, cega congênita.

As normas estabelecidas para auxiliar os deficientes visuais, muitas vezes, não atendem suas reais necessidades - não há muita preocupação pelos órgãos responsáveis em saber, diretamente com os deficientes, quais as melhores formas de atendê-los, além de que, muitas dessas normas nem são cumpridas ou são de forma errônea.

Existe uma enorme dificuldade em atender este público, em específico. Cada deficiente possui sua particularidade, seja pela doença que adquiriu, se é congênito, se é portador de baixa visão e qual o estado da mesma, suas memórias ativas, mas principalmente, de seu aprendizado cartográfico. Através de conversas informais com a pesquisadora, o entrevistado relatou que os cegos congênitos não conseguem entender a cartografia euclidiana, e sendo um mapa tátil, dificilmente entenderiam o espaço representado. No geral, nenhuma sinalização isolada atende suas necessidades, é necessário um conjunto destas para que consiga suprir as diversas particularidades dos usuários. Ao chegarem em um ambiente fechado e totalmente inédito, se não existir nenhuma forma de sinalização adequada, o deficiente visual fica totalmente à mercê da ajuda de terceiros.

Um exemplo dado pelo entrevistado seria, também, a incompreensão de onde estão quando seguem o piso tátil. Chegam ao relevo que indica atenção (as bolinhas) 
mas não sabem exatamente o que os esperam, se chegaram ao seu destino, se é algum obstáculo - uma sugestão dada foi a utilização de relevos diferenciados. São medidas simples que podem facilitar muito a vida destas pessoas. O áudio é um sistema que mais auxilia nestas questões, mais fácil de ser compreendido e é universal, uma vez que, cada vez mais, menos pessoas aprendem o Braille.

\subsection{Produto Final}

O produto desenvolvido se trata de um mapa tátil do Instituto de Artes e Design da Universidade Federal de Juiz de Fora.

De acordo com toda pesquisa realizada, foi observado a importância das texturas. Através delas é possível proporcionar uma grande diferenciação no produto e é de um entendimento mais universal, podendo se criar ambientes distintos apenas com relevos diferentes. De acordo com isto, foi desenvolvido um mapa tátil do primeiro andar do Instituto, com a finalidade de cada pavimento possuir o seu, com texturas diferentes para cada elemento que compõe o local, como salas de aula, banheiro, cantina, auditório, estúdio, D.A, e copa - além das indicativas de parede e o caminho a ser percorrido, sendo este em baixo relevo para diferenciar dos demais elementos componentes do mapa. Este percurso só será melhor compreendido se possuir um piso tátil por todo IAD seguindo as mesmas orientações dispostas no modelo - foi uma medida tomada para que houvesse uma melhor compreensão do trajeto, mas sem a presença do piso tátil, não terá a mesma eficiência.

A aplicação das cores é para auxiliar os portadores de baixa visão, proporcionando o alto contraste, de acordo com a norma ABNT NBR 9050, além de deixar o mapa mais agradável. Todos os demais elementos seguem as exigências da mesma norma, assim como a altura de 1 (um) metro do suporte em relação ao piso e uma inclinação de até 15으 do mesmo.

Para a confecção do mapa foi utilizada uma escala de 1:200, baseada nas plantas cedidas pela Pró-Reitoria de Infraestrutura e Pró-Reitoria de Planejamento da Universidade Federal de Juiz de Fora. As plantas possuem elaboração da arquiteta Adriana de Assis (CREA - 57530/D) e Responsável Técnico David C. Mosqueira (CREA 99939/D - MG). Alguns detalhes da planta foram suprimidos para a confecção por questões de tamanho aplicado à escala que poderiam não atender muito bem ao tato, causando dúvidas ou até mesmo durante a impressão ocasionar em estragos.

O modelo completo foi confeccionado com materiais alternativos, como placa de isopor pluma, papel paraná, tintas para artesanato, cola, entre outros. Esta foi uma medida tomada para que pudesse ter o modelo completo, uma vez que não haveria prazo para a impressão em 3D de todas as partes.

As texturas foram elaboradas com um grau de distinção bem definido, para que não ocorressem dúvidas no momento de tatear. Após o teste das texturas, percebeuse a necessidade da alteração de algumas dimensões, deixando os relevos menores e com mais espaços entre si, e isto foi modificado no modelo final. O nível das paredes é mais elevado que as texturas para auxiliar na distinção do limite do ambiente. O " $X$ " representa o local onde o mapa está fixado no ambiente do prédio. O suporte do mapa é feito de aço inoxidável, com formas simples para ser fixado na parede por parafusos. Sua tipologia diferenciada dos demais se dá pela redução de custo; uma chapa de metal dobrada e fixada à parede, além de ser algo diferenciado, sairia mais em conta em relação às plataformas mais convencionais. $E$ para que o deficiente visual o 
localize, contém piso tátil em seu torno, com duplicação do piso, para que o deficiente o identifique com maior antecedência. A parte superior do suporte também pode ser utilizada como um sinalizador para quem enxerga e identificar do que se trata o mapa.

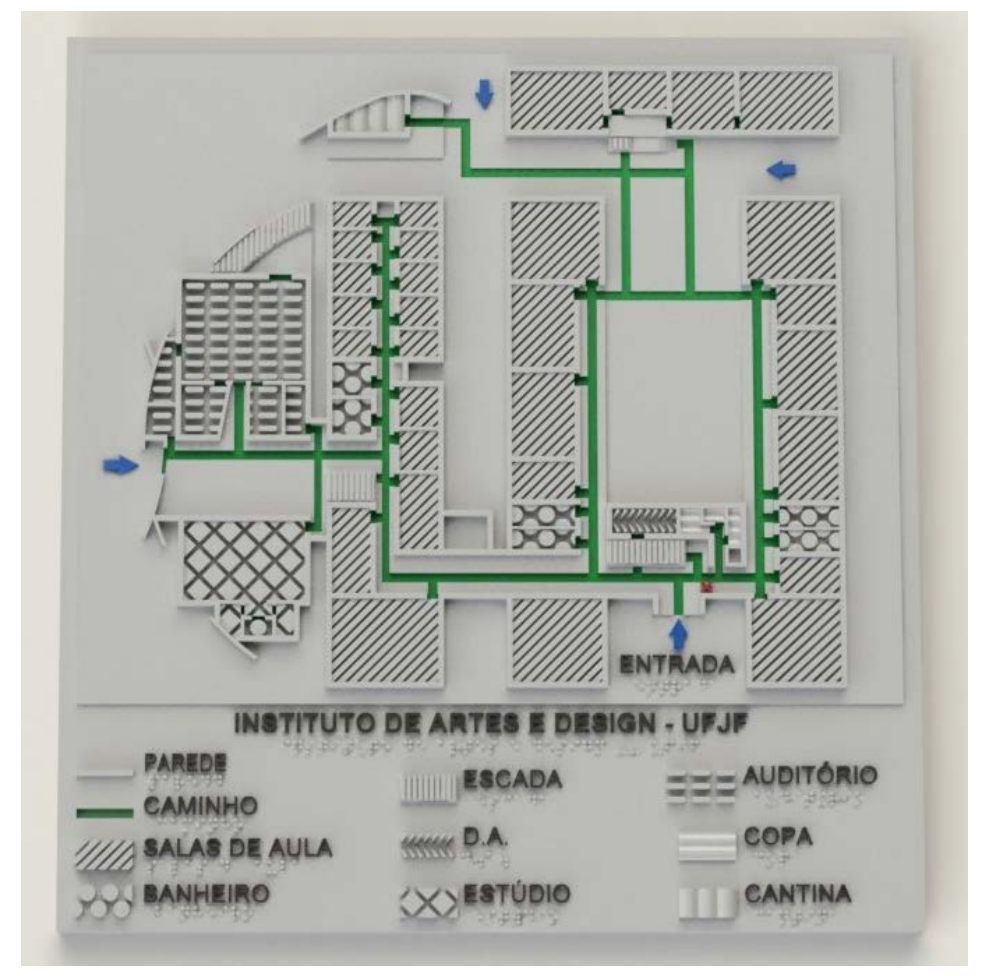

Figura 4 - Render da vista superior do mapa tátil do Instituto de Artes e Design. Fonte: autores
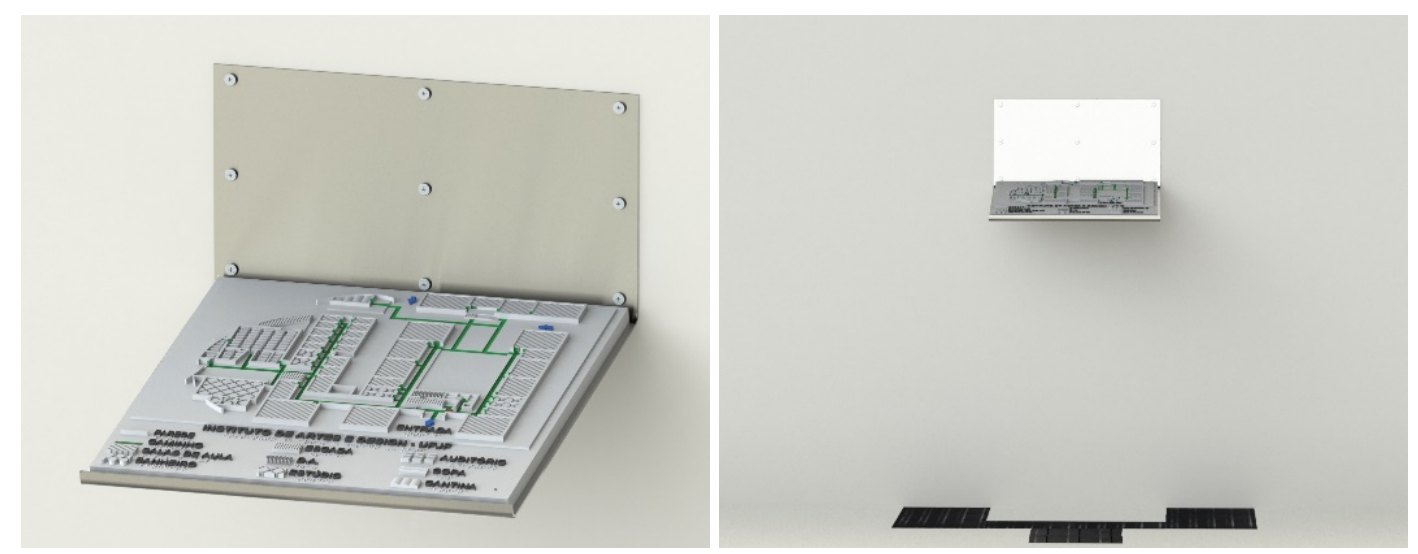

Figura 5 - Renderes da aplicação do mapa tátil em seu suporte e a devida sinalização de piso tátil. Fonte: autores 

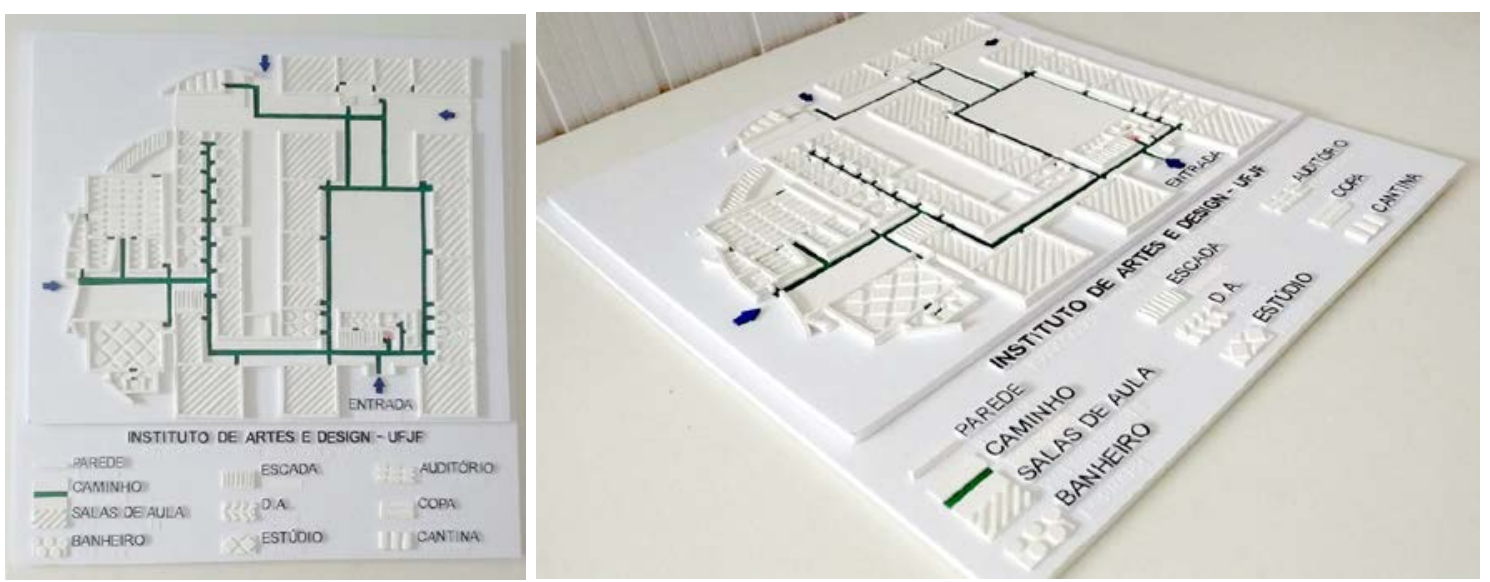

Figura 6 - Fotografia do modelo feito com materiais alternativos.

Fonte: autores
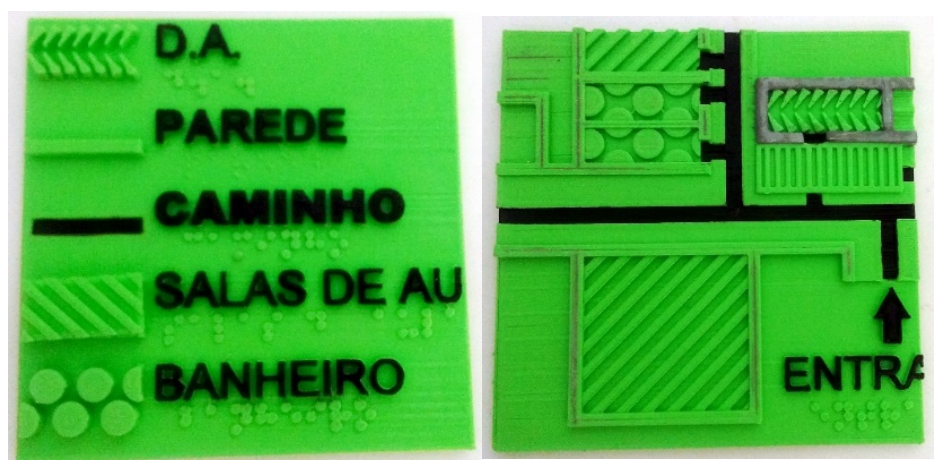

Figura 7 - Partes do mapa impressas em 3D. Elaboradas para realizar o teste das texturas e Braille. Fonte: autores

\section{CONCLUSÃO}

O presente projeto necessita de teste por usuários para comprovar sua eficácia. Foi realizado teste com duas pessoas que possuem a deficiência visual, a senhora Terezinha Martins de Araujo, cega congênita, e seu esposo José do Carmo Reis, portador de baixa visão.

O deficiente que possui cegueira congênita tem grande dificuldade em interpretar a cartografia tátil. É muito difícil compreenderem o espaço que os cerca representados de forma reduzida e em uma superfície plana. A usuária fez os testes em pequenas placas impressas em 3D contendo parte da legenda e parte do mapa, elaboradas apenas para o teste antes de fabricar o mapa por completo. Ela conseguiu compreender que as texturas diferentes representavam ambientes distintos, seus limites com as paredes mais elevadas auxiliaram nesta questão.

Com o apoio de seu esposo, de maneira muito didática, foi lhe explicado o que compunha o mapa e assimilando ao que ela entende por ambiente às formas encontradas, pedindo que ela imaginasse os ambientes de sua casa com texturas diferentes no piso e que não existissem mais paredes, o caminho foi exemplificado como os corredores com piso tátil, e as direções dos corredores foram mostradas comparando com ruas em que ela tem contato e possui o mapa mental. Com muita explicação sobre isto, ela conseguiu compreender as formas, porém, sem toda esta 
ajuda e didática não seria possível ou seria necessário muito tempo de estudo para perceber melhor o seu conteúdo. Em algumas texturas houve um pouco de dificuldade em assimilar a da legenda com o mapa.

O senhor José do Carmo possui baixa visão, há 13 (treze) anos, e uma percepção ambiental muito nítida. $O$ alto contraste atendeu sua necessidade, mas também encontrou alguma dificuldade em identificar alguns relevos.

As peças foram relativamente pequenas em relação à dimensão total do mapa tátil e levar somente duas amostras causou um pouco de dúvida. Tanto em relação à disposição das peças quanto com a continuidade do mapa, além de não ser possível testar todas as texturas. Se houvessem mais peças, de preferência completo, a compreensão do mapa poderia ser testada de forma mais efetiva.

Os resultados obtidos ficaram restritos aos poucos usuários entrevistados. Com a experiência de outras pessoas que possuem outros níveis de cegueira poderia se obter um resultado mais definitivo, pois o principal fator que causou as dificuldades, foi a experiência de vida do usuário, por seu nível de deficiência e nunca ter tido contato com um objeto semelhante.

Independentemente dos resultados obtidos pela pesquisa, o fator mais importante se dá ao estudo de novas formas de acessibilidade para quem realmente precisa. O mundo precisa se adaptar mais e um relato muito significativo feito pelos usuários foi que a Terezinha não cogita enxergar um dia, este não é seu desejo, mas sim ter um mundo mais acessível às suas necessidades.

\section{REFERÊNCIAS}

ABNT. Associação Brasileira de Normas Técnicas. NBR 9050: Acessibilidade de pessoas portadoras de deficiências a edificações, espaço, mobiliário e equipamento urbano. Rio de Janeiro: ABNT, 2015.

ABATE, Tania Pietzschke; ONO, Rosaria; KOWALTOWSKI, Doris Catharine Cornelie Knatz. Metodologia de pesquisa em arquitetura e design: instrumentos de coleta de dados 3D destinados a alunos cegos. Brasília: 2013

ALVARENGA, Bárbara de Almeida. Memória Visual e Imagem Corporal em indivíduos com Cegueira Adquirida. Faculdade de Fisioterapia, Universidade Federal de Juiz de Fora. Juiz de Fora, 2014.

ANDRADE, Mateus Gomes de. et al. Design de uma nova linha de pisos táteis: um projeto interdisciplinar para acessibilidade. In: Anais... IV Congresso internacional de pesquisa em design. Rio de Janeiro, out, 2007. apud DIAS, Regina Álvares; ESTANISLAU, Sarah S. Braga; BAHIA, Isabela Pontello. Maquetes e mapas táteis: Diretrizes para projeto, seleção de materiais e técnicas. Ação Ergonômica. ABERGO. Vol 9, número 1. 2014

ASHBY, Michael; JOHNSON, Kara. Materiais e Design: arte e ciência da seleção de materiais no design de produto. Tradução de Arlete Simille Marques. 2o edição de tradução. Rio de Janeiro: Elsevier, 2011.

ASSOCIAÇÃO DOS CEGOS. Disponível em: <http://www.acegosjf.com.br/> . Acesso em 15 dez. 2015 
BBC. British Broadcasting Corporation. Apresenta um aplicativo que 'lê' o mundo para os cegos através de voluntários. Disponível em:

<http://www.bbc.com/portuguese/noticias/2015/01/150129_app_deficientes_lab> . Acesso em: 17 dez. 2015

D'ABREU, João Vilhete Viegas; SOUSA, Danielle Dantas de; RAVASCHIO, Patrícia de Paula; PUPO, Deise Tallarico; MARTINS, Valeria dos Santos Gouveia. Maquete tátil da biblioteca central Cesar Latter da UNICAMP: Uma experiência. 2007.

DIAS, Regina Álvares; ESTANISLAU, Sarah S. Braga; BAHIA, Isabela Pontello. Maquetes e mapas táteis: Diretrizes para projeto, seleção de materiais e técnicas. Ação Ergonômica. ABERGO. Vol 9, número 1. 2014.

FERREIRA, M. E. dos S. Construção de um mapa tátil do campus Seropédica da UFRRJ. Departamento de Engenharia, Instituto de Tecnologia, Universidade Federal Rural do Rio de Janeiro, 2008.

G1. Central de informações Globo. Apresenta dados do IBGE do censo de 2010 sobre deficiências. Disponível em: <g1.globo.com/brasil/noticia/2012/04/239-dosbrasileiros-declaram-ter-alguma-deficiencia-diz-ibge.html.> Acesso em: 04 dez 2015. Instituto Benjamin Constant. Um olhar sobre a cegueira. Disponível em: <www.ibc.gov.br/?itemid=93\#more>. Acesso em: 04 dez. 2015 LIMA, Marco Antônio Magalhães. Introdução aos materiais e Processos para Designers. Rio de Janeiro: Editora Ciência Moderna Ltda. 2006

MILAN, Luis Fernando. Maquetes táteis: infográficos tridimensionais para a orientação espacial de deficientes visuais. PARC Pesquisa em Arquitetura e Construção, v. 1, n. 2 , 2008.

MORA, Adriana Bolaños. Design inclusivo centrado no usuário: diretrizes para ações de inclusão de pessoas cegas em museus. Dissertação (mestrado) - Universidade Federal do Rio Grande do Sul. Porto Alegre. 2012.

MORAES, Dijon de. Metaprojeto: o design do design. São Paulo: Blucher, 2010. MOTTIN, Artur Caron. et al. Acessibilidade para todos: Maquete tátil do Congresso Nacional - Um estudo de caso. Brasília, DF, 2008.

ONU. Nações Unidas no Brasil. Apresenta dados da OMS relativo aos cegos no mundo. Disponível em: <www.nacoesunidas.org/oms-afirma-que-existem-39-milhoes-decegos-no-mundo/>. Acesso em: 04 dez. 2015.

PORTAL DO BRASIL. Governo Brasileiro. Setor de infraestrutura. Desenvolvem aplicativo adaptado para smartphones de usuários cegos. Disponível em: <http://www.brasil.gov.br/infraestrutura/2013/12/aplicativo-melhora-vida-dedeficientes-visuais>. Acesso em: 17 dez. 2015

VENTORINI, Silvia Elena. A experiência como fator determinante na representação espacial do deficiente visual. $151 \mathrm{f}$. Dissertação (mestrado) - Universidade Estadual Paulista, Instituto de Geociências e Ciências Exatas, Rio Claro, 2007.

VOLPATO, Neri (editor). et al. Prototipagem Rápida: Tecnologias e aplicações. 1. ed. São Paulo: Blucher, 2007. 